\title{
NA ESCOLA SE APRENDE QUE A DIFERENÇA FAZ A DIFERENÇA
}

\author{
Berenice Bento \\ Universidade Federal do Rio Grande do Norte
}

\begin{abstract}
Resumo: Neste artigo, problematizo os limites das instituições sociais em lidar com os sujeitos que fogem às normas de gênero. Deter-me-ei principalmente nas respostas que a escola tem dado aos/às estudantes que apresentam performances de gênero que fogem ao considerado normal.
\end{abstract}

Palavras-chave: transexualidade; travestilidade; escola; violência; gênero.

\section{Introdução}

Em 1984, uma revista exibiu a manchete: "A mulher mais bonita do Brasil é um homem". Pela primeira vez na história do país, a sociedade começou a se deparar com as confusões de gênero em escala midiática. ' Roberta Close trouxe para a cena nacional o olhar incrédulo de pessoas que a examinavam e buscavam naquele corpo exuberante sinais de masculinidade. Por muito tempo Roberta Close reivindicou sua identidade de gênero. Afirmava que era uma mulher transexual e precisava mudar seu nome e sexo nos seus documentos. Sem muita pressa, a justiça lhe respondia: "Não, você nasceu homem e nada se pode fazer contra esse destino biológico". Por muitos anos, Roberta teve que se submeter ao constrangimento de portar documentos que negavam sua existência social.

A aproximação com a transexualidade e travestilidade ${ }^{2}$ é reveladora das convenções sociais sobre a masculinidade e a feminilidade. Diariamente profissionais da saúde, juízes/ as, advogados/as, professores/as, parlamentares, amigos/as e familiares são instados a se posicionar e encontrar sentidos para as demandas de pessoas que reivindicam o pertencimento ao gênero distinto daquele que lhes foi imposto.

Pessoas transexuais e travestis são expulsas de casa, não conseguem estudar, não conseguem emprego, são excluídas de todos os campos sociais, entram na justiça para solicitar a mudança do nome e do sexo; enfim, um conjunto de instituições sociais é posto

\section{Copyright (c) 2011 by Revista Estudos Feministas.}

${ }^{1}$ As reflexões deste artigo são parte da pesquisa que realizei para meu pós-doutorado no Nesprom/Ceam/ UnB. Agradeço ao Professor Dr. Elioenai Dornelles Alves, pela tutoria, e ao CNPq, pelo financiamento da pesquisa.

2 Para discussão sobre as identidades travesti e transexual, ver Berenice BENTO, 2008. 
em ação toda vez que alguém afirma: "não me reconheço nesse corpo, não me identifico com o gênero imposto; quero uma cirurgia corretiva do meu sexo, não suporto esses seios que me aprisionam ao destino materno; quero mudar minha identidade civil". Essas anunciações reverberam nas instituições como sentenças proferidas por uma pessoa transtornada, sem condições de significar suas dores.

O objetivo deste artigo é apresentar reflexões que possibilitem problematizar os limites das instituições sociais em lidar com essas demandas. Deter-me-ei principalmente nas respostas que a escola tem dado aos/às estudantes que apresentam performances de gênero que fogem ao considerado normal.

\section{As tecnologias que fazem o gênero}

Observe uma mulher grávida. Conforme os meses passam, aumenta a ansiedade para saber o sexo da criança. Quando o sexo da criança é revelado, o que era uma abstração passa a ter concretude. O feto já não é feto, é um menino ou uma menina. Essa revelação evoca um conjunto de expectativas e suposições em torno de um corpo que ainda é uma promessa. ${ }^{3}$

Enquanto o aparelho da ecografia passeia pela barriga da mãe, ela espera ansiosa as palavras mágicas que irão desencadear as expectativas. A ansiedade da mãe aumenta quando o aparelho começa a fixar-se ali, na genitália, e só termina quando há o anúncio das palavras mágicas: o sexo da criança. A materialidade do corpo só adquire vida inteligível quando se anuncia o sexo do feto. Toda a eficácia simbólica das palavras proferidas pelo/a médico/a está em seu poder mágico de gerar expectativas que serão materializadas posteriormente em brinquedos, cores, modelos de roupas e projetos para o/ a futuro/a filho/a antes mesmo de o corpo vir ao mundo.

Quando a criança nasce, encontrará uma complexa rede de desejos e expectativas para seu futuro, levando-se em consideração para projetá-la o fato de ser um/a menino/ menina, ou seja, ser um corpo que tem um/a pênis/vagina. Essas expectativas são estruturadas numa complexa rede de pressuposições sobre comportamentos, gostos e subjetividades que acabam por antecipar o efeito que se supunha causa.

Os brinquedos, as cores das roupas e outros acessórios que comporão o enxoval são escolhidos levando-se em conta o que seria mais apropriado e natural para uma vagina $e$ um pênis. No entanto, como é possível afirmar que todas as crianças que nascem com vagina gostam de rosa, de bonecas, de brinquedos que não exigem muita força, energia e inteligência? Aquilo que evocamos como um dado natural, o corpo-sexuado, é resultado das normas de gênero. Como afirmar que existe um referente natural, original, para se vivenciar o gênero, se ao nascermos já encontramos as estruturas funcionando e determinando o certo e o errado, o normal e o patológico? O original já nasce "contaminado" pela cultura. Antes de nascer, o corpo já está inscrito em um campo discursivo.

A interpelação "é um/a menino/a" não apenas cria expectativas e gera suposições sobre o futuro daquele corpo que ganha visibilidade através dessa tecnologia, seus efeitos são protéticos: faz corpos. ${ }^{4} \mathrm{O}$ gênero, portanto, é o resultado de tecnologias sofisticadas que produzem corpos-sexuais. As interpelações do/a médico/a fazem parte de um projeto

\footnotetext{
${ }^{3}$ Beatriz PRECIADO, 2002.

4 PRECIADO, 2002.
} 
mais amplo que não antecede ao gênero, mas o produz. A suposta descrição do sexo do feto funciona como um batismo que permite ao corpo adentrar na categoria "humanidade". ${ }^{5}$

Quando se diz "é um menino!", não se está descrevendo um menino, mas criando um conjunto de expectativas para aquele corpo que será construído como "menino". O ato da linguagem, nessa perspectiva, não é uma representação da realidade, mas uma interpretação construtora de significados. John Austin chamou essa característica da linguagem de "capacidade performática". ${ }^{\circ}$ Quando se diz "menino/menina", não se está descrevendo uma situação, mas produzindo masculinidades e feminilidades condicionadas ao órgão genital.

Uma criança que recebe de presente bonequinhas para cuidar, dar de mamar, fogõezinhos e panelinhas onde predomina a cor rosa está sendo preparada para o gênero feminino (passiva, cuidadosa, bondosa) e terá na maternidade o melhor e único lugar para exercer esses atributos. Ou então, se essa criança ganha revólveres, carros, bolas e outros brinquedos que estimulam a competição e exigem esforços mentais e corporais está em curso o trabalho de fabricação do corpo para o mundo público. Os brinquedos continuam o trabalho do/a médico/a que proferiu as palavras mágicas: produzem o feminino e o masculino. Funcionam como próteses identitórias.

As experiências de trânsito entre os gêneros demonstram que não somos predestinados a cumprir os desejos de nossas estruturas corpóreas. O sistema não consegue a unidade desejada. Há corpos que escapam ao processo de produção dos gêneros inteligíveis e, ao fazê-lo, se põem em risco porque desobedeceram às normas de gênero, ao mesmo tempo revelam as possibilidades de transformação dessas mesmas normas. Esse processo de fuga do cárcere dos corpos-sexuados é marcado por dores, conflitos e medos. As dúvidas "por que eu não gosto dessas roupas? Por que odeio tudo que é de menina? Por que tenho esse corpo?" levam os sujeitos que vivem em conflito com as normas de gênero a localizar em si a explicação para suas dores, a sentir-se uma aberração, uma coisa impossível de existir. Quais os mecanismos sociais que produzem nas subjetividades essa sensação de anormalidade? Como as instituições operam para serem eficazes no seu intento de naturalizar os gêneros? Como o centro produz e se alimenta perversamente das margens?

\section{Reiterações e heteroterrorismo}

Após o nascimento da criança, as tecnologias discursivas dirigem-se à preparação do corpo para que desempenhe com êxito o gênero. O mundo infantil se constrói sobre proibições e afirmações. Essa pedagogia dos gêneros hegemônicos tem como objetivo preparar os corpos para a vida referenciada na heterossexualidade, construída a partir da ideologia da complementaridade dos sexos. As "confusões" nos "papéis" provocam, direta e imediatamente, "perturbações" na orientação sexual, supõem os defensores do binarismo.

\footnotetext{
${ }^{5}$ A discussão sobre os batismos linguísticos remete às reflexões de John Langshaw AUSTIN, 1990, sobre a capacidade de a linguagem criar realidades. Para esse autor, é necessário apontar que a linguagem não se resume a descrever a realidade, mas é uma de suas produtoras. No caso da linguagem científica, a tarefa de desvelamento dessa função é consideravelmente complexa, pois sua eficácia consiste na ideia da sua suposta capacidade em descrever dada realidade de forma neutra.

${ }^{\circ}$ AUSTIN, 1990.
} 
As reiterações que produzem os gêneros e a heterossexualidade são marcadas por um terrorismo contínuo. Há um heteroterrorismo a cada enunciado que incentiva ou inibe comportamentos, a cada insulto ou piada homofóbica. ${ }^{7}$ Se um menino gosta de brincar de boneca, os heteroterroristas afirmarão: "Pare com isso! Isso não é coisa de menino!". A cada reiteração do/a pai/mãe ou professor/a, a cada "menino não chora!", "comporta-se como menina!", "isso é coisa de bicha!", a subjetividade daquele que é o objeto dessas reiterações é minada.

Essas verdades são repetidas por diversos caminhos, por várias instituições. A invisibilidade é um desses mecanismos, e quando "o outro", "o estranho", "o abjeto", aparece no discurso é para ser eliminado. É um processo de dar vida, através do discurso, para imediatamente matá-lo. Quando um/a pai/mãe firma "Isso é coisa de bicha", essa sentença tem múltiplos efeitos. A criança não entende muito bem o que é aquele "bicho-papão" que provoca a ira da/o mãe/pai. Sabe que não quer ser rejeitado. Sabe, portanto, que não poderá (ainda que não saiba como) agir como uma bicha. Essas interdições ficam mais claras ao longo da vida. A bicha, o sapatão e o afeminado são essenciais para realimentar a heterossexualidade, não por serem estranhos, externos a ela, mas porque a constituem ou, conforme Jacques Derrida, a diferença gera aquilo que ela proíbe, "tornando possível a própria coisa que ela torna impossível". ${ }^{8}$ A transexualidade seria, portanto, a materialização do impossível, o inominável, aquilo que transcende a capacidade de compreensão.

Nascemos e somos apresentados a uma única possibilidade de construirmos sentidos identitários para nossas sexualidades e gêneros. Há um controle minucioso na produção da heterossexualidade. $\mathrm{E}$, como as práticas sexuais se dão na esfera do privado, será através do gênero que se tentará controlar e produzir a heterossexualidade. Se meninos gostam de brincar de boneca ou meninas odeiam brincar de casinha, logo terá um olhar atento para alertar aos pais que seu/sua filho/a tem comportamentos "estranhos". Daí o perigo que a transexualidade e a travestilidade representam para as normas de gênero, à medida que reivindicam o gênero em discordância com o corpo-sexuado.

A questão central quando se discutem trânsitos identitários é desvincular as identidades de um ponto determinante. Hegemonicamente o gênero e a sexualidade se expressam unidos. As "confusões" que uma criança faz ao misturar os dois mundos (o masculino e o feminino) são interpretadas pelo olhar atencioso das instituições, como um indicador de uma homossexualidade latente. Nessa hora, entra o controle produtor: "Isso não é coisa de menino/a!". Controle produtor porque produz masculinidades e feminilidades.

Passamos a interiorizar essas verdades como se fossem uma pele, algo que está conosco desde sempre, o que nos faz esquecer os inúmeros, cotidianos, reiterados "ensinamentos": a sexualidade normal e natural é a heterossexualidade. Depois de uma minuciosa e contínua engenharia social para produzir corpos-sexuados que tenham na heterossexualidade a única possibilidade humana de viver a sexualidade, como se pode continuar atribuindo à natureza a responsabilidade daquilo que é o resultado de tecnologias gerenciadas e produzidas pelas instituições sociais?

\footnotetext{
${ }^{7}$ Utilizo "homofobia" conforme proposto por Guacira Lopes LOURO, 1997, p. 29: "Homofobia, o medo voltado contra os(as) homossexuais, pode-se expressar numa espécie de 'terror em relação à perda do gênero', ou seja, no terror de não ser mais considerado como um homem ou uma mulher 'reais' ou 'autênticos'". Estou consciente de que há especificidades na forma como esse terror atualiza-se quando referente às lésbicas, às pessoas transexuais e travestis, daí está de acordo com aqueles/as que preferem "lesbofobia" e "transfobia" para marcar e desvendar as singularidades das violências. No entanto, como não discutirei essas especificidades, prefiro o conceito de homofobia de Guacira Lopes Louro por ter um caráter mais amplo. ${ }^{8}$ Jacques DERRIDA, 1974, p. 143.
} 
Reiterar significa que é através das práticas, de uma interpretação em ato das normas de gênero, que o gênero existe. O gênero adquire vida através das roupas que compõem o corpo, dos gestos, dos olhares, ou seja, de uma estilística definida como apropriada. São esses sinais exteriores, postos em ação, que estabilizam e dão visibilidade ao corpo. Essas infindáveis repetições funcionam como citações, e cada ato é uma citação daquelas verdades estabelecidas para os gêneros, tendo como fundamento para sua existência a crença de que são determinados pela natureza.

Quando se age e se deseja reproduzir a/o mulher/homem "de verdade", desejando que cada ato seja reconhecido como aquele que nos posiciona legitimamente na ordem de gênero, nem sempre o resultado corresponde àquilo definido e aceito socialmente como atos próprios a um/a homem/mulher. Se as ações não conseguem corresponder às expectativas estruturadas a partir de suposições, abre-se uma possibilidade para se desestabilizarem as normas de gênero, que geralmente utilizam da violência física e/ou simbólica para manter essas práticas às margens do considerado humanamente normal. O processo de naturalização das identidades e a patologização fazem parte desse processo de produção das margens, local habitado pelos seres abjetos.

As formas idealizadas dos gêneros geram hierarquia e exclusão. Os regimes de verdades estipulam que determinadas expressões relacionadas com o gênero são falsas, enquanto outras são verdadeiras e originais, condenando a uma morte em vida, exilando em si mesmo os sujeitos que não se ajustam às idealizações.

Os gêneros inteligíveis obedecem à seguinte lógica: vagina-mulher-feminilidade versus pênis-homem-masculinidade. A heterossexualidade daria coerência às diferenças binárias entre os gêneros. A complementaridade natural seria a prova inquestionável de que a humanidade é necessariamente heterossexual e de que os gêneros só têm sentido quando relacionados às capacidades inerentes de cada corpo. Através das performances de gênero, a sociedade controla as possíveis sexualidades desviantes. Será a heterossexualidade que justificará a necessidade de se alimentarem/produzirem cotidianamente os gêneros binários, em processos de retroalimentação. Os gêneros inteligíveis estão condicionados à heterossexualidade, e essa precisa da complementaridade dos gêneros para justificar-se como norma.

Há uma amarração, uma costura, no sentido de que o corpo reflete o sexo e o gênero só pode ser entendido, só adquire vida, quando referido a essa relação. As performatividades de gênero que se articulam fora dessa amarração são postas às margens, analisadas como identidades transtornadas, anormais, psicóticas, aberrações da natureza, coisas esquisitas. A repetição permite a eficiência dos atos performativos que sustentam e reforçam as identidades hegemônicas, mas, também, são as repetições deslocadas do contexto natural dos sexos, a exemplo da transexualidade, que possibilitam a emergência de práticas que interrompem a reprodução das normas de gênero e, ao fazê-lo, explicitam o caráter excludente da categoria "humano" das pessoas que reconstroem suas posições identitárias transitando e, portanto, negando a precedência explicativa do biológico. ${ }^{9}$

Os "normais" negam-se a reconhecer a presença da margem no centro como elemento estruturante e indispensável. Daí as instituições eliminarem-na obsessivamente por insultos, leis, castigos, assassinatos. As mortes das travestis e transexuais se caracterizam pelo ritual de perversidade. Não basta um tiro, uma facada. Não basta matar uma vez. Mesmo diante do corpo moribundo, o assassino continua atirando e golpeando. Quem está sendo morto? A margem? Não seria o medo de o centro admitir que ela (a transexual/

9 Judith BUTLER, 1998, 1999 e 2002. 
a margem) me habita e me apavora? Antes matá-la. Antes agir em nome da norma, da lei e fazer a assepsia que garantirá o bom funcionamento e a regulação das normas. Outra solução "mais eficaz" é o confinamento dos "seres abjetos" aos limites dos compêndios médicos e trazê-los à vida humana por uma aguilhada que marca um código abrasado a cada relatório médico que diagnostica um "transtorno".

\section{Escola: espaço de reprodução do HeteroTerrorismo}

São múltiplas as violências cometidas contra as pessoas transexuais. A patologização social dessa experiência identitária talvez seja a mais cruel, pois irradia a convicção de que são pessoas inferiores. Cruzar os limites dos gêneros é colocar-se em uma posição de risco. Quando se afirma que existe uma norma de gênero, deve-se pensar em regras, leis, interdições e punições.

São corriqueiras as notícias de pessoas transexuais e travestis assassinadas no Brasil sem que haja apuração e punição dos/as culpados/as. Acaba-se produzindo uma hierarquia das mortes: algumas merecem mais atenção do que outras. De modo geral, na lógica jurídica, um dos critérios para se definir a posição que cada assassinato deve ocupar na hierarquia dos operadores do Direito parece ser a conduta da vítima em vida. Nessa cruel taxonomia, casos de pessoas transexuais assassinadas ocupam a posição mais inferior. É como se houvesse um subtexto: "quem mandou se comportar assim". Essa taxonomia acaba (re)produzindo uma pedagogia da intolerância. A vítima é metamorfoseada em ré em um processo perverso de esvaziá-la de qualquer humanidade.

A possibilidade de se reivindicarem direitos humanos se restringe a um grupo muito reduzido de sujeitos que têm atributos que o lançam ao topo da hierarquia: são heterossexuais, brancos, homens masculinos, membros da elite econômica/intelectual/ política. $O$ afastamento desses pontos qualificadores de humanidade reduz a capacidade de o sujeito entrar na esfera dos direitos e de reivindicá-los. Os direitos humanos se transformam, nesse processo, num arco-íris: lindo de se ver, impossível de se alcançar. As normas de gênero só conferem vida àqueles seres que estão "ajustados" a essa expectativa.

A produção de seres abjetos e poluentes (gays, lésbicas, travestis, transexuais, e todos os seres que fogem à norma de gênero) e a desumanização do humano são fundamentais para garantir a reprodução da heteronormatividade. A escola é uma das instituições centrais nesse projeto. O DSM-IV ${ }^{10}$ reconhece o papel dessa instituição em alertar os pais e as mães sobre os comportamentos desviantes dos/as filhos/as. Segundo o DSM-IV,

o isolamento e o ostracismo contribuem para a baixa auto-estima e podem levar à aversão e abandono da escola. O ostracismo e a zombaria por parte dos seus pares são seqüelas especialmente comuns para meninos com o transtorno [...].

Tipicamente, as crianças são encaminhadas [ao psicólogo] por ocasião de seu ingresso na escola, em vista da preocupação dos pais de que aquilo que consideravam uma "fase" parece não estar sendo superado (PSIQWEB, 2008).

\footnotetext{
${ }^{10}$ Manual de Diagnóstico e Estatísticas de Transtornos Mentais, da Associação Psiquiátrica Americana (APA). Em 1980, a APA aprovou a terceira versão DSM incluindo a transexualidade no rol dos Transtornos de Identidade de Gênero, no capítulo dedicado aos Distúrbios de Identidade de Gênero. Em sua quarta versão, estabeleceu os critérios diagnósticos para as chamadas "perturbações mentais, incluindo componentes descritivas, de diagnóstico e de tratamento, constituindo um instrumento de trabalho de referência para os profissionais da saúde mental em todo o mundo". Sobre o DSM, ver BENTO, 2008; PSIQWEB (2008); e Jane Araújo RUSSO, 2004.
}

554 Estudos Feministas, Florianópolis, 19(2): 548-559, maio-agosto/201 1 
O que acontece nas salas de aula e nos pátios das escolas? Por que o DSM-IV aponta o ingresso na escola como a fase mais crítica? A escola, que se apresenta como uma instituição incapaz de lidar com a diferença e a pluralidade, funciona como uma das principais instituições guardiãs das normas de gênero e produtora da heterossexualidade. Para os casos em que as crianças são levadas a deixar a escola por não suportarem o ambiente hostil, é limitador falarmos em "evasão".

No entanto, não existem indicadores para medir a homofobia de uma sociedade e, quando se fala de escola, tudo aparece sob o manto invisibilizante da evasão. Na verdade, há um desejo de eliminar e excluir aqueles que "contaminam" o espaço escolar. Há um processo de expulsão, e não de evasão. É importante diferenciar "evasão" de "expulsão", pois, ao apontar com maior precisão as causas que levam crianças a não frequentarem o espaço escolar, se terá como enfrentar com eficácia os dilemas que constituem o cotidiano escolar, entre eles, a intolerância alimentada pela homofobia.

\section{O cotidiano escolar}

Imagine o sofrimento de uma criança que acorda, põe o uniforme da escola e, enquanto se prepara, pensa: "mais um dia em que terei que suportar aquele menino me chamando de veadinho; mais um dia em que terei que ficar o recreio inteiro sozinho porque ninguém gosta de brincar e ficar comigo". Essa é a sensação descrita por pessoas que vivem a experiência transexual que entrevistei ${ }^{11}$ quando se lembram da escola - instituição lembrada como um espaço de terror:

Na escola, quando me chamavam de veado ou de macho-fêmea, eu chorava, me afastava de todo mundo, não saía para o recreio. Eu só tenho a $3^{a}$ série completa. Eu parei em 96... Eu parei de estudar no meio da $4^{a}$ série. Notas boas... Por causa desse preconceito que não agüentava. Não agüentei o preconceito de me chamarem de macho-fêmea, de veado, de travesti, essas coisas todas. (Kátia)

Meu Deus, que horror era tudo aquilo! Eu não saía para o recreio. Eu achava que esse órgão não tinha a menor importância, que todo mundo me reconheceria como uma mulher. Muitas vezes puxavam meu cabelo e eu tinha que brigar, principalmente quando me chamavam de veadinho. (Marcela)

Agora eu estou tentando voltar a estudar. Quando eu era pequeno, todo dia eu voltava para casa todo machucado. Me chamavam de macho-fêmea, sapatão. Eu não aceitava. A diretora chamava minha mãe. Era uma confusão. Até que um dia, eu parei de ir. (Pedro)

Eu acreditava que poderia viver normalmente como uma senhora, sem problemas, que isto que tenho no meio das pernas não faria diferença. Eu não pensei que esse sexo anatômico fosse provocar transtornos para mim. Mas, eu pensava uma coisa e a vida me mostrou outra. Quando eu fui para a escola, aos dez anos, comecei a me dar conta da diferença e a notar que aquilo que não fazia diferença para mim, fazia a diferença. É aí que começaram os problemas. (Joana)

Essas falas nos revelam os limites da escola em lidar com as diferenças. Para se compreenderem os motivos que fazem da escola um espaço destinado, fundamentalmente, a reproduzir os valores hegemônicos, é necessário sair desse espaço, ampliar nosso olhar para a própria forma como a sociedade produz as verdades sobre o que deve ser reproduzido, quais os comportamentos de gênero sancionados e por que outros são silenciados e invisibilizados, qual a sexualidade construída como "normal" e como gênero e sexualidade

"Ao longo de três anos (2000 a 2003) realizei trabalho de campo para minha tese de doutorado sobre transexualidade. Citarei nomes e falas de alguns/umas entrevistados/as. Sobre a pesquisa, ver BENTO, 2006. 
se articulam na reprodução social. Essas questões não podem ser respondidas exclusivamente nos limites da escola. Há um projeto social, uma engenharia de produção de corpos normais, que extrapola os muros da escola, mas que encontrará nesse espaço um terreno fértil de disseminação.

É um equívoco falar em "diferença ou diversidade no ambiente escolar" como se houvesse o lado da igualdade, onde habitam os/as que agem naturalmente de acordo com os valores hegemônicos e os outros, ou diferentes. Quando, de fato, a diferença é anterior, é constitutiva dessa suposta igualdade. Portanto, não se trata de "saber conviver", mas considerar que a humanidade se organiza e se estrutura na e pela diferença. Se tivermos essa premissa evidente, talvez possamos inverter a lógica: não se trata de identificar "o estranho" como "o diferente", mas de pensar que estranho é ser igual e na intensa e reiterada violência despendida para se produzir o hegemônico transfigurado em uma igualdade natural. Quando compreendemos a produção das identidades de gênero marcada por uma profunda violência, passamos a entender a homofobia enquanto uma prática e um valor que atravessa e organiza as relações sociais, distribui poder e regula comportamentos, inclusive no espaço escolar.

As pesquisas realizadas nas paradas do Orgulho Gay ${ }^{12}$ apontaram que, de um total de 629 entrevistados/as, $26,8 \%$ relataram que foram marginalizados/as por professores/as ou colegas na escola ou faculdade. Esse percentual aumenta conforme diminui a faixa etária. Segundo o relatório da pesquisa, "nada menos que $40,4 \%$ dos adolescentes entre 15 e 18 anos foram vítimas dessa experiência [margilização/discriminação]. Entre jovens de 19 e 21 anos, 31,3\% referiram-se a discriminações na escola ou na faculdade". ${ }^{13}$

Na pesquisa sobre juventudes e sexualidade realizada por Mary Garcia Castro et al., ${ }^{14}$ há um pequeno capítulo sobre homofobia. Utilizando a técnica de grupos focais, foi possível chegar a alguns depoimentos de professoras/es sobre a presença de alunas/os tidas/os como homossexuais no espaço escolar:

Tem preconceito porque tem um menino que é meio afeminado. Travesti. Muitos jogam ovos nele. Muitos ficam tirando "sarro". Muitos não chegam perto dele. Parece que ele tem uma doença contagiosa. Eles julgam pela aparência e não conhece para saber o que e como ele se sente.'

Outros depoimentos:

Na minha sala, tinha um menino homossexual e a galera, os meninos, o perturbaram tanto até ele sair da escola, não voltou. Ele chegava assim, todo assim, e os meninos ficavam perturbando, fazendo hora, brincando. Acabou que teve de sair da escola porque foi muito forte a história. ${ }^{16}$

Teve um menino que era homossexual, os alunos ficavam chateando ele e os professores não ligavam, até que ele desistiu de estudar.

Os relatos de discriminações não são acompanhados de histórias de professores/as que tenham realizado discussões em sala de aula ou na escola sobre respeito, diversidade e diferença. O fato de o/a aluno/a interromper os estudos parece algo inevitável, natural, sugerindo, portanto, que essa discussão não diz respeito ao ambiente escolar e que a

${ }^{12}$ Sérgio CARRARA e Sílvia RAMOS, 2005.

${ }^{13}$ CARRARA e RAMOS, 2005, p. 80.

${ }^{14}$ Mary Garcia CASTRO et al., 2004.

${ }^{15}$ CASTRO et al., 2004, p. 288.

${ }^{16}$ CASTRO et al., 2004, p. 287.

${ }_{17}$ CASTRO et al., 2004, p. 286.

556 Estudos Feministas, Florianópolis, 19(2): 548-559, maio-agosto/2011 
instituição nada pode fazer para proteger suas/seus alunas/os vítimas desse tipo de violência, a não ser assinar o termo de transferência.

Nessa mesma pesquisa, perguntou-se a estudantes se consideravam a homossexualidade uma doença. Em Fortaleza, 30,5\% dos meninos e 18,1\% das meninas acreditam se tratar de uma doença. No Rio de Janeiro, esse percentual é de $23,2 \%$ entre os meninos e de 7,6\% entre as meninas. Em Goiânia, é de $22,4 \%$ entre os meninos e de $13,9 \%$ entre as meninas. ${ }^{18}$

De forma tímida, esses dados nos mostram que há uma patologização das identidades. A luta empreendida pelos movimentos sociais e por estudos desconstrucionistas que desnaturalizem as sexualidades e os gêneros que se organizam fora do binarismo ainda tem um longo caminho a ser seguido.

Outra pergunta dizia respeito às ações consideradas mais violentas. ${ }^{19}$

TABELA 1 - Proporção de alunos de ensino fundamental e máedio, por sexo e por ordem de indicação, segundo as cinco ações consideradas mais violentas, BRASIL - Conjunto de 14 cidades (2000)

\begin{tabular}{lcc}
\hline & Masculino & Feminino \\
\hline Atirar em alguém & 82,6 & 86,3 \\
Estuprar & 68,5 & 84,0 \\
Bater em homossexuais & 36,1 & 47,8 \\
Usar drogas & 48,1 & 46,0 \\
Roubar & 45,3 & 44,6 \\
Andar armado & 44,0 & 42,1 \\
\hline
\end{tabular}

Fonte: CASTRO et al., 2004.

Tanto entre os meninos quanto entre as meninas, atirar em alguém aparece como a ação mais violenta. No entanto, "bater em homossexuais" é considerado pelos meninos como a ação menos violenta. Entre as meninas essa é a terceira ação mais violenta. Por que roubar, usar drogas e andar armado são atos mais agressivos? Talvez a questão anterior responda a essa pergunta. A patologização das identidades autoriza e confere poder àqueles que estão no centro para realizar com as próprias mãos a "assepsia" que deixará a sociedade livre da contaminação. É a patologização das identidades distribuindo humanidade, proferindo sentenças e castigos aos que ousaram romper a lei. É o heteroterrorismo em pleno processo de funcionamento, interiorizado, reproduzindo-se com toda eficácia. Os divergentes sexuais e de gênero só poderão existir em espaços apropriados, nos compêndios do saber médico e nos espaços confessionais das clínicas. Lá os encontraremos, todos hierarquizados, classificados e especificados.

O medo do contágio é reforçado quando $44,9 \%$ dos/as alunos/as entrevistados/as em Vitória (ES) afirmaram que não gostariam de ter homossexuais como amigos/as. A escola, tida como um espaço fundamental no processo de socialização e de construções de vínculos, revela seu lado mais perverso. Os depoimentos de Kátia, Marcela, Pedro e Joana reforçam a tese do medo de contágio. As agressões na hora do recreio e os reiterados insultos a que eram submetidas/os revelam a necessidade de se diferenciarem analiticamente os indicadores que compõem a chamada "evasão escolar".

${ }^{18}$ CASTRO et al., 2004

19 CASTRO et al., 2004, p. 279 
A natureza da violência que leva uma criança a deixar de frequentar a escola porque tem que trabalhar para ajudar a família não é da mesma ordem daquela que não consegue se concentrar nos conteúdos transmitidos porque é "diferente". Daí a importância de pesquisas (com recortes de gênero e sexualidade) que demonstrem os encaixes dos indicadores de "sucesso" e "fracasso", deslocando o olhar dos conteúdos visíveis para os invisíveis.

A escola não é uma ilha. Embora saibamos que historicamente tem cumprido principalmente o papel de reprodutora de uma visão naturalizada das relações sociais, notamos que os debates que atravessam a sociedade brasileira também podem se sentir nas salas de aula. Há um saudável incômodo de educadores/as, gestores/as das políticas públicas e do ativismo em trazer para o cotidiano escolar a reflexão dos direitos humanos em uma perspectiva ampla. Está em curso, portanto, a produção incessante de contradiscursos, e a escola, de múltiplas formas, está inserida nessa disputa.

\section{Nas frestas das normas habitam as resistências}

Há uma disputa acirrada, muitas vezes negada, entre os discursos. Aqueles que são hegemônicos têm poderosas instituições que repetem em uníssono: a normalidade da existência tem como fundamento a diferença sexual. O saber médico é uma dessas poderosas instituições. Sua legitimidade está na capacidade de produzir verdades inquestionáveis. Por ser "neutro", há uma crença de que esse saber descreve a natureza, quando, de fato, produz a natureza em sua imagem e semelhança.

Embora saibamos que os discursos religiosos sobre as condutas de gênero e as práticas sexuais continuem atuando nas subjetividades e produzindo julgamento, no espaço escolar, no entanto, é mais "fácil" utilizar os discursos médicos para legitimar a violência. A censura "Não faça isso! É pecado!" foi substituída por "isso não é normal! Comporte-se como um/a menino/a!". O pecaminoso foi ressignificado no anormal. ${ }^{20}$

A eficácia desse discurso está em produzir nos sujeitos a incômoda e terrível certeza de que ele não é normal e de que, se ele se sente fora do lugar, é porque não existe lugar para ele. Há um processo incessante de produção de anormalidade. Ao problematizar a visão patologizante das identidades, terminamos por encontrar as normas de gênero. As reivindicações de identidades que exigem direitos são o desdobramento inevitável de uma ordem de gênero que estabelece que a inteligibilidade dos gêneros está no corpo. Dois corpos, dois gêneros, uma sexualidade. Nessa perspectiva binária, o masculino e o feminino seriam a expressão ou formulação cultural da diferença natural dos sexos. Ao localizar nas instituições a explicação para a gênese das experiências identitárias, inverto a lógica: são as normas de gênero que possibilitam a emergência de conflitos identitários com essas mesmas normas.

Nesse processo de desnaturalização, o foco explicativo para a constituição das identidades desloca-se do indivíduo para as genealogias dos discursos, que limitam a categoria "humanidade" apenas a duas possibilidades excludentes: ou você tem pênis ou vagina. Ou você é mulher ou é homem. Ou você é masculino ou feminino, mas sejamos todos heterossexuais. Nada de ambiguidade, um horror a indeterminação.

E como se produz a ideia de doença, de identidades transtornadas? Quando se localiza exclusivamente no indivíduo a fonte explicativa para a emergência do conflito identitário. Portanto, o passo seguinte é pensar que se pode "curá-lo". Mediante as intervenções cirúrgicas simbólicas, pode-se recuperá-lo, fazer o sujeito desviante vir para o centro, aceitar a heterossexualidade como sendo a única forma de vivenciar a sexualidade.

${ }^{20}$ Michel FOUCAULT, 2001.

558 Estudos Feministas, Florianópolis, 19(2): 548-559, maio-agosto/2011 
O que está posto é uma evidente disputa com os valores hegemônicos que localizam e conferem direitos apenas a uma parcela da humanidade. Essa disputa revela a precariedade de um sistema de gênero e sexualidade assentado no império do biológico e, consequentemente, na genitalização das relações sociais. Essa precariedade pode ser observada quando milhões de pessoas ocupam espaços públicos demandando humanidade e tencionando os limites dos direitos humanos, quando pessoas transexuais reivindicam direitos e explicitam o debate sobre a diversidade/diferença de gênero.

\section{Referências bibliográficas}

AUSTIN, John Langshaw. Quando dizer é fazer: palavras e ação. Porto Alegre: Artes Médicas, 1990.

BENTO, Berenice. A (re)invenção do corpo: sexualidade e gênero na experiência transexual. Rio de Janeiro: Garamond/Clam, 2006.

O que é transexualidade. São Paulo: Brasiliense, 2008. (Primeiros Passos).

BUTLER, Judith. "Gênero, trajetórias e perspectivas". Cadernos Pagu, Campinas, n. 11 , p. 11 42, 1998. 1999.

Gender Trouble: Feminism and the Subversion of Identity. New York/London: Routledge,

. "Criticamente subversiva". In: JIMÉNEZ, Rafael Mérida (Ed.). Sexualidades transgresoras: una antología de estudios queer. Barcelona: Icaria, 2002. p. 22-34.

CASTRO, Mary Garcia et al. Juventude e sexualidade. Brasília: Unesco, 2004.

CARRARA, Sérgio; RAMOS, Sílvia. Política, direitos, violência e homossexualidade: Pesquisa 9a. Parada do Orgulho GLBT - Rio 2004. Rio de Janeiro: Clam, 2005.

DERRIDA, Jacques. Of Grammatology. Baltimore: Johns Hopkins University Press, 1974.

FOUCAULT, Michel. Os anormais. São Paulo: Martins Fontes, 2001.

LOURO, Guacira Lopes. Gênero, sexualidade e educação: uma perspectiva pósestruturalista. Rio de Janeiro: Vozes, 1997.

PRECIADO, Beatriz. Manifiesto contra-sexual: prácticas subversivas de identidad sexual. Madrid: Pensamiento Opera Prima, 2002.

PSIQWEB. Disponível: <http://www.psiqweb.med.br>. Acesso em: 18 mar. 2011.

RUSSO, Jane Araújo. "Do desvio ao transtorno: a medicalização da sexualidade na nosografia psiquiátrica contemporânea". In: PISCITELLI, Adriana et al. Sexualidade e saberes: convenções e fronteiras. Rio de Janeiro: Garamond, 2004. p. 81-94.

[Recebido em 15 de março de 2011 e aceito para publicação em 10 de maio de 2011]

\section{In School We Learn that the Difference Makes a Difference}

Abstract: This article explores the limits of social institutions in dealing with the subjects fleeing gender norms. I will focus mainly on the responses given by schools to students whose gender performance departs from what is considered normal.

Key Words: Transsexuality; Travestism; School; Violence; Gender. 